Natural Hazards and Earth System Sciences (2003) 3: 407-422

(C) European Geosciences Union 2003

Natural Hazards and Earth System Sciences

\title{
A methodology for physically based rockfall hazard assessment
}

\author{
G. B. Crosta and F. Agliardi \\ Università degli Studi di Milano-Bicocca, Piazza della Scienza, 4, I-20126 Milano, Italy
}

Received: 9 September 2002 - Accepted: 21 November 2002

\begin{abstract}
Rockfall hazard assessment is not simple to achieve in practice and sound, physically based assessment methodologies are still missing. The mobility of rockfalls implies a more difficult hazard definition with respect to other slope instabilities with minimal runout. Rockfall hazard assessment involves complex definitions for "occurrence probability" and "intensity". This paper is an attempt to evaluate rockfall hazard using the results of 3-D numerical modelling on a topography described by a DEM. Maps portraying the maximum frequency of passages, velocity and height of blocks at each model cell, are easily combined in a GIS in order to produce physically based rockfall hazard maps. Different methods are suggested and discussed for rockfall hazard mapping at a regional and local scale both along linear features or within exposed areas. An objective approach based on three-dimensional matrixes providing both a positional "Rockfall Hazard Index" and a "Rockfall Hazard Vector" is presented. The opportunity of combining different parameters in the 3-D matrixes has been evaluated to better express the relative increase in hazard. Furthermore, the sensitivity of the hazard index with respect to the included variables and their combinations is preliminarily discussed in order to constrain as objective as possible assessment criteria.
\end{abstract}

\section{Introduction}

Rockfalls are the among the most common landslide types in mountain areas. Despite usually involving limited volumes (Rochet, 1987), rockfalls are characterised by high energy and mobility, making them a major cause of landslide fatalities (Guzzetti, 2000). Rockfalls can be triggered by earthquakes (Kobayashi et al., 1990), rainfall or freeze-andthaw cycles (Matsuoka and Sakai, 1999) or the progressive weathering of rock material and discontinuities in suitable

Correspondence to: G. B. Crosta

(giovannib.crosta@unimib.it) climatic conditions. They originate from cliffs of different sizes (from few metres to hundreds of metres high) and natures (lithologic, structural, etc.), and involve a wide range of volumes (Rochet, 1987; Hungr and Evans, 1988). Rockfalls are among the most destructive mass movements, and pose a severe threat to humans, properties and utilities where they occur (Cancelli and Crosta, 1993; Bunce et al., 1997). For these reasons rockfall hazard and risk assessment are of major interest to technicians, administrators and local planners (Cancelli and Crosta, 1993; Fell, 1994; Fell and Hartford, 1997; Crosta and Locatelli, 1999; Guzzetti et al., 1999). Rockfall hazard assessment is not simple to achieve in practice and sound, physically based assessment methodologies are still missing.

Despite the fact that rockfalls are common, few attempts have been made to evaluate the related hazard, and the associated risk, in a spatially distributed way (Van Dijke and Van Westen, 1990; Cancelli and Crosta, 1993; Crosta and Locatelli, 1999; Wieczorek et al., 1999), or along transportation or utility corridors (Evans and Hungr, 1993; Bunce et al., 1997; Hungr at al., 1999). Most of the available hazard assessment methods are empirical (Pierson et al., 1990; Dussauge-Peisser et al., 2002) or semi-empirical (Cancelli and Crosta, 1993; Rouiller and Marro, 1997; Crosta and Locatelli, 1999). They often consider only the onset (or triggering) probability of rockfalls, without any characterisation or modelling of rockfall trajectories in 2-D or 3-D. This leads to a subjective definition and zonation of rockfall hazard, making the validation and comparison of different methodologies difficult (Mazzoccola and Sciesa, 2000; Interreg IIC, 2001).

This paper presents a physically-based procedure to evaluate rockfall hazard using the results of 3-D numerical modelling, performed through an original simulation code. Computing rockfall trajectories is mandatory to achieve objective rockfall hazard assessment. In addition, the use of 3D modelling is fundamental to face different classes of hazard problems (Crosta and Locatelli, 1999), namely Fig. 1: point-like (single elements, small areas), linear or corridorlike (lifelines, routes) and areal (urban areas, areas subjected 


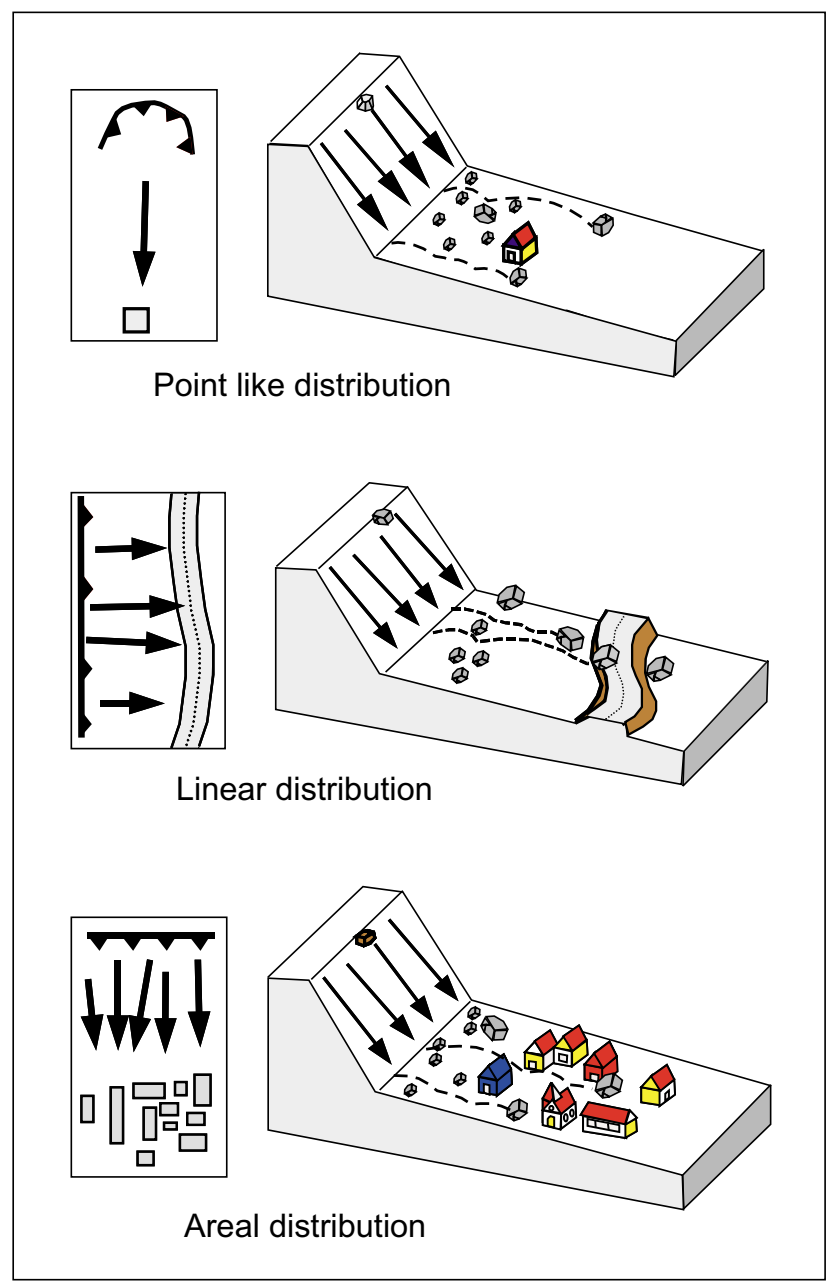

Fig. 1. Different categories of rockfall hazard problems.

to planning). These problems are characterised by increasingly difficult hazard assessment. In this study, the results of 3-D rockfall models performed at both regional and local scales, have been used to test the method on areal and linear problems. The use of 3-D matrixes providing a positional "Rockfall Hazard Index" and a "Rockfall Hazard Vector" is presented and discussed. Furthermore, the sensitivity of hazard maps to the included variables and their combination is discussed in order to constrain the assessment criteria as objectively as possible.

\section{Numerical modelling of rockfalls}

Rockfall phenomena start by the detachment of blocks from their original position. This phase is followed by free falling, bouncing, rolling or sliding (Broili, 1973; Varnes, 1978; Bozzolo and Pamini, 1986), with falling blocks losing energy at impact points or by friction. Kinematic, dynamic or empirical equations (Falcetta, 1985; Bozzolo and Pamini, 1986; Descouedres and Zimmerman, 1987; Rochet, 1987; Bozzolo et al., 1988; Pfeiffer and Bowen, 1989; Evans and Hungr,
1993; Wieczorek et al., 1999) can be used to model rockfall processes and define regions subjected to this hazard.

Rockfall dynamics is a complex function of the location of the detachment point and the geometry and mechanical properties of both the block and the slope. Theoretically, knowing the initial conditions, the slope geometry, and the relationships describing the energy loss at impact or by rolling, it should be possible to compute the position and velocity of a block at any time. Nevertheless, relevant parameters are difficult to ascertain both in space and time, even for an observed event. Usually, the geometrical and geomechanical properties of the blocks (size, shape, strength, fracturing) and of the slope (gradient, length and roughness, longitudinal and transversal concavities and convexities, grain size distribution, elastic moduli, water content, etc.), and the exact location of the source areas are unknown. The same can be said for the variability of the controlling parameters. In addition, the energy lost at each impact or during rolling depends on a variety of factors including the velocity of the block and the impact angle, the block to slope contact type (block corner, edge or face), and the presence and density of vegetation (Bozzolo and Pamini, 1986; Cancelli and Crosta, 1993; Azzoni and De Freitas, 1995; Jones et al., 2000). These parameters are difficult to quantify both precisely and accurately at any spatial scale. Thus, "contact functions" relating the block kinematics (in terms of velocity) or dynamics (in terms of energy) before and after the impact, are introduced to model the energy loss at each impact point. Such functions are usually expressed as restitution and friction coefficients and regarded as material constants even if, as already mentioned, they include the effects of many different controlling factors (type and thickness, texture and structure of slope deposits, block size and geometry, angle and velocity of impact, geometry of the impact, vegetation, soil moisture content, etc.).

When rockfall trajectories are computed along a limited number of 2-D slope profiles defined a priori, the interpretation of the results and its extension to neighbouring areas may not be straightforward (or unique), and require extensive engineering judgment in order to be used for hazard assessment purposes (Crosta and Locatelli, 1999). In fact, the three-dimensional nature of actual slope geometry (e.g. the presence of chutes and channels, convexities and longitudinal ridges), strongly affect the trajectories and the partition of kinetic energy into translational and rotational components (Chau et al., 2002). Different computer codes and algorithms have been proposed (Bozzolo and Pamini, 1986; Descouedres and Zimmermann, 1987; Bozzolo et al., 1988; Evans and Hungr, 1988; Pfeiffer and Bowen, 1989; Azzoni et al., 1995; Stevens, 1998; Jones et al., 2000), but few 3-D models have been developed (Descouedres and Zimmermann, 1987; Guzzetti et al., 2002). Available software performs 2-D or 3-D simulations using a kinematic (i.e. lumped-mass), a dynamic, or a "hybrid" (i.e. kinematic for free fall and dynamic for impact and/or for rolling) approach (Crosta and Agliardi, 2000). Tools are also provided to cope with the variability of input data (Bozzolo and Pamini, 1986; Descouedres and Zimmermann, 1987; Pfeiffer and Bowen, 1989; Scioldo, 


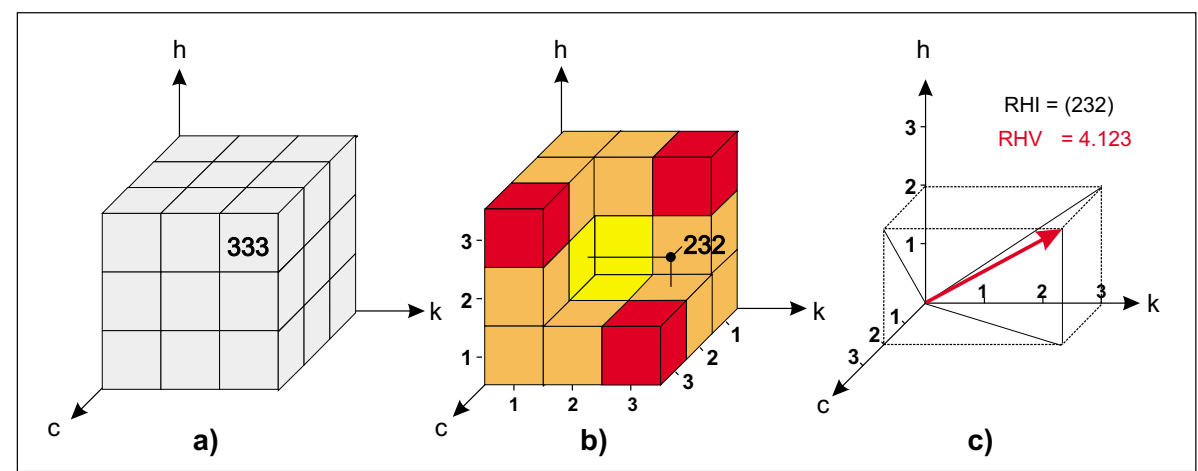

Fig. 2. The three-dimensional matrix $c k h$, used for rockfall hazard assessment. (a) General definition of the positional Rockfall Hazard Index, RHI; (b) splitted matrix cube with ranked RHI values; (c) Rockfall Hazard Vector $(\boldsymbol{R} \boldsymbol{H} \boldsymbol{V})$ concept.

1991; Azzoni et al., 1995; Stevens, 1998; Jones et al., 2000).

Keeping in mind the aforementioned problems, we designed and developed an original rockfall simulation program, named STONE (Agliardi et al., 2001; Agliardi and Crosta, 2002; Guzzetti et al., 2002; Agliardi and Crosta, 2003). The program computes rockfall trajectories in 3-D, and allows one to prepare spatially distributed maps of the frequency and kinematics of rockfalls. The code has some specific characteristics concerning the modelling approach and the preparation of input data, namely:

- a lumped mass algorithm allows modelling free fall, impact and rolling motions in a 3-D framework;

- topography is provided as a Digital Elevation Model (DEM), without resolution restrictions, and a vector topography is recalculated starting from the DEM;

- spatially distributed input data are provided, without limitations to the number of land units introduced to describe surface lithology and land use;

- rockfall sources can be defined as points, lines or polygons; a different number of blocks can be launched from each source cell, allowing simulating different onset probabilities of rockfalls;

- stochastic modelling through a "pseudo-random" approach can be performed and repeated;

- air drag and block fracturing are not taken in account for simplicity;

- the program accepts input data and produces outputs in a raster EsriTM GridAscii format, allowing for integration with GIS environments for pre- and post-processing of input data and model results.

STONE requires the following input data:

- a raster grid containing elevation data (DEM);

- a grid of the source cells and of the number of boulders to be launched from each cell;
- three grids containing the values for the normal and tangential restitution coefficients and the rolling friction coefficient;

- a parameter file specifying the input filenames and the main controlling parameters and variability.

The following 2-D-raster and 3-D-vector outputs are provided:

- raster maps which portray at each cell: the cumulative count of rockfall transits; the maximum computed velocity; and the largest flying height;

- vector outputs which provide instantaneous velocity and fly height at each sampled point of the computed fall paths.

As above mentioned, STONE allows for the inherent natural variability of the input data to be taken in account by launching a variable number of blocks from each detachment cell. This can simulate both a different zone-by-zone onset probability of rockfalls and the stochastic nature of the rockfall process. The initial projection angle, the dynamic rolling friction coefficient, and the normal and tangential restitution coefficients can be varied randomly within pre-defined ranges for each of the multiple launched blocks. In order to consider the dependence of the restitution coefficients on block mass and velocity, a couple of semi-empirical relationships (Pfeiffer and Bowen, 1989; Stevens, 1998) have been implemented in the code. Consequently, the normal and tangential restitution coefficients can be scaled according to the imposed block mass or the computed impact velocity. No dependence of the normal restitution coefficient on the impact angle has been introduced in the code at this moment.

\section{Physically-based rockfall hazard assessment}

\subsection{Suitable strategies}

Rockfall modelling aims to define, for a specified "design block", the fall path, the maximum runout distance, the envelope of trajectories and the velocity and energy distribution 


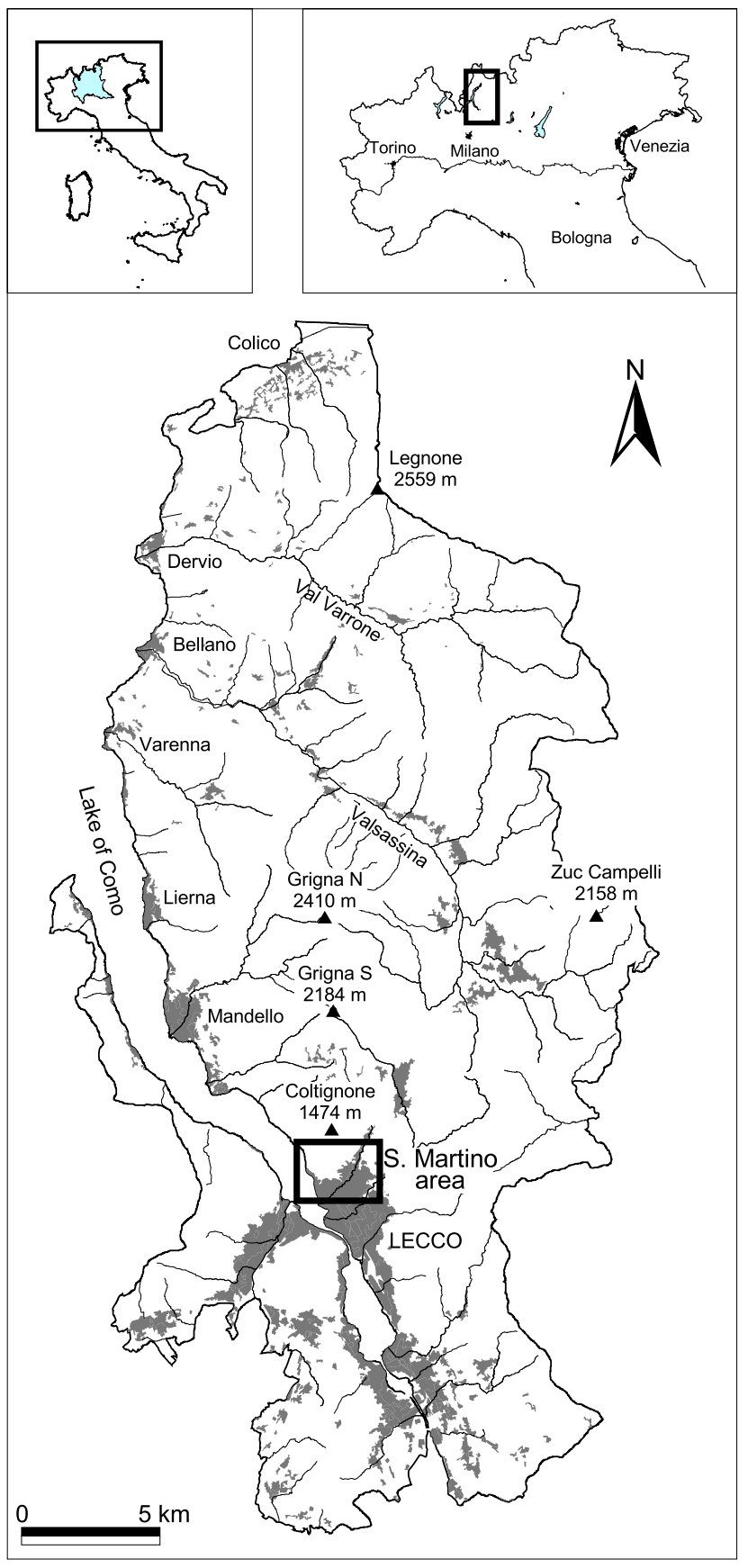

Fig. 3. Location map of the study areas in the Lombardy region (northern Italy): the Lecco Province and the Mt. S. MartinoColtignone area.

along them. This information results in rockfall hazard and risk assessment, and in the design and planning of countermeasures (Spang, 1987; Cancelli and Crosta, 1993; Crosta and Locatelli, 1999). In engineering practice, these studies are usually performed along specific 2-D slope profiles.

Landslide hazard has been usually defined in the literature as the probability of occurrence of a landslide of given magnitude, in a pre-defined period of time, and within a given area (Varnes et al., 1984; Fell, 1994; Fell and Hartford,
1997; Guzzetti et al., 1999; Crosta et al., 2001). This definition incorporates the concepts of spatial location, magnitude and frequency of occurrence of a landslide. Spatial location refers to the ability to forecast where a landslide will occur; magnitude refers to the prediction of the geometrical and mechanical intensity (i.e. the amount of energy involved), and frequency refers to the forecasting of the temporal recurrence of the landslide event (Varnes, 1984; Einstein, 1988). Thus, the simplest rockfall hazard map should portray the probability of occurrence of rockfalls of pre-defined magnitude within a given area.

The high mobility of rockfalls (as is the case with debris flows and rock avalanches) implies a major difference in hazard assessment with respect to other slope instability phenomena characterised by minimal expansion. The local recurrence probability for high mobility phenomena must derive from the detachment and the transit components (Cancelli and Crosta, 1993; Crosta and Locatelli, 1999; Interreg IIC, 2001), both of which vary in space, along the same trajectory and moving laterally to another one. Furthermore, rockfall intensity must be evaluated along each rockfall path. As a consequence, rockfall hazard can be better defined as the probability of occurrence (including detachment and transit) of a rockfall of given magnitude, in a pre-defined period of time and at any location along a slope susceptible to its transit.

The definition of hazard introduced above involves an increased level of information needed for objective hazard assessment. In fact, it is not enough to know the total runout length and the associated probability to reach this maximum distance. Elements at risk can be located at different distances along the rockfall path. Thus, the intensity and probability of rockfall occurrence at a given location must be defined along the entire falling path. Since probability and intensity vary along the slope as complex functions of the mechanical and geometrical characteristics of both the slope and the falling blocks, this definition calls for a physically sound modelling of rockfall motion along a slope. The local occurrence probability derives from the combination of the onset probability (related to the geomechanical susceptibility of rock masses to fail) and the transit or impact probability at a given location (related to the motion of falling blocks). Rockfall intensity is a complex function of mass, velocity or energy and fly height of blocks. Thus, the intensity can be defined in different ways depending on the adopted physical description and destructiveness criterion.

The raster or vector maps prepared by STONE outline the areas where rockfalls are expected to occur and their kinematic features. Thus, they are likely to be combined to provide a spatial assessment of rockfall hazard (Agliardi et al., 2002). The count of rockfall trajectories is a proxy for the probability of occurrence of rockfalls. At any cell, the map portrays the chance of being crossed by a rockfall trajectory, resulting from the number of launched blocks, the variability of the controlling parameters, the local morphology and the DEM detail. The maximum computed rockfall velocity and fly height provide separate information on rockfall intensity 
to be associated with the block design mass. A distributed set of block mass values can be inserted in the model for a translational kinetic energy-based computation of the intensity.

Two main questions arise. First, what is the best way to compute and represent hazard? Second, how can different hazard levels be ranked? According to our approach, rockfall hazard can be derived by the combination of different independent components, depending on the adopted definition of intensity. For example, hazard could be function of three, equally important components, one probabilistic (count, $c$ ) and two kinematic (velocity, $v$, and fly height, $h$ ). One more option consists in the use of the rockfall count $(c)$, the computed translational kinetic energy $(k)$ and the fly height $(h)$. In this way, rockfall dynamics is introduced by means of $k$. The fly height could be eventually considered as a weak indicator of hazard level. This is because it is relevant only for prediction of impact on elements of different vertical size or on the influence on down-slope located points. As a consequence, hazard could be a function of the count $(c)$ velocity $(v)$ and the mass $(m)$.

We have introduced a "dynamic" component in rockfall hazard assessment by considering hazard as a function of the computed rockfall count $(c)$, kinetic energy $(k)$ and fly height $(h)$. The three components are conveniently represented in a 3-D space, by defining a 3-D matrix which portrays hazard as a function of the adopted parameters (Fig. 2).

The rockfall hazard conditions defined by the 3-D matrixes can be expressed using a "Rockfall Hazard Index" (Fig. 2) defined as RHI $=(c k h)$. The digits of the RHI are reclassified values of the adopted variables. The RHI has a positional meaning, i.e. hazard is identified by a specific position in the hazard parameter space. The approach is affected by some conceptual problems. Are all the possible values of RHI realistic? How can RHI values be ranked to define the hazard level and perform zonation? As to the first question, if the values of the controlling parameters (for example $c, k$, and $h$ ) are ranked into $n$ classes ( 0 to $n$, in order to allow for combination into a 3-digit index), RHI $=(000)$ will correspond to the origin of the 3-D hazard space, representing a condition where rockfalls are not expected. In a similar way, any RHI value including a zero digit is unrealistic since it indicates no rockfall occurrence, and the lowest acceptable RHI digit value is 1 . As to hazard ranking (Fig. 2), rockfall hazard increases at a maximum rate along the diagonal line that trisects the hazard space. Other RHI values represent intermediate hazard conditions. From a purely geometrical point of view, all the points lying on planes perpendicular to the diagonal line should exhibit the same hazard level. Actually, since the input parameters are reclassified into discrete classes, the hazard index is also discrete. In addition, many different real situations could be outlined on a "constant hazard" plane, involving different occurrence probabilities and different amount of kinetic energy and, thus, requiring different mitigation approaches. The use of a positional index allows one to keep track of the contribution of each variable to the hazard and, thus, to outline "why" a location on the slope
Table 1. Parameter reclassification scheme used in the Rockfall Hazard Index/vector procedure. Note that the values of $c$ are normalised according to different approaches depending on the modelling scale. See text for explanation

\begin{tabular}{ccccc}
\hline class & \multicolumn{2}{c}{$c$ (normalised) } & $k$ & $h$ \\
- & regional scale & local scale & $(\mathrm{kJ})$ & $(\mathrm{m})$ \\
\hline 1 & $<0.2$ & $<0.01$ & $\leq 700$ & $\leq 4$ \\
2 & $0.2-1$ & $0.01-0.1$ & $700-2500$ & $4-10$ \\
3 & $>1$ & $>0.1$ & $\geq 2500$ & $\geq 10$ \\
\hline
\end{tabular}

is characterised by a given hazard level. Nevertheless, the positional nature of the RHI index hampers the direct ranking of hazard. For example (Fig. 2), it will be difficult to decide if $\mathrm{RHI}=(113)$ portrays a higher hazard than $\mathrm{RHI}=(311)$ or RHI $=(121)$. Thus, the RHI index needs to be translated into a sequential one. Thus, we will introduce the concept of Rockfall Hazard Vector $(\boldsymbol{R} \boldsymbol{H} \boldsymbol{V})$, its magnitude to be used as hazard ranking criterion (Fig. 2). The hazard vector approach can be figured as an "onion skin" approach, with increasing hazard level moving outward.

\subsection{Rockfall Hazard Index/Vector procedure}

The effectiveness of a hazard map relies on different elements. First, a physically based modelling approach is considered fundamental, because it allows for an accurate description of rockfall phenomena and decreases the amount of engineering judgement required. Accuracy of the input data is another major element controlling the quality of the hazard maps. Finally, practical efficacy of hazard maps also depends on their clarity, i.e. on the fragmentation of the information provided. In fact, a useful hazard map should portray as many as possible different areas homogeneous with respect to hazard, allowing decision makers to optimise land planning. Nevertheless, excessive fragmentation of the information provided by the map could be misleading when planning urban development. For example, small "safe" isolated areas in a generally "unsafe" area could be not suitable for developing in practice.

Starting from the aforementioned considerations, we developed a new rockfall hazard assessment procedure: this is conceived to take in account as many physical aspects of rockfall as possible, to be easy to use and to provide meaningful hazard maps, to be translated into planning tools with little further effort. The method considers three main parameters which are computed directly or indirectly by STONE, namely: the rockfall count $c$, the translational kinetic energy $k=0.5 \mathrm{~m} \mathrm{v}^{2}$, and the fly height $h$. According to the method, rockfall hazard is expressed by a "Rockfall Hazard Index" $\mathrm{RHI}=(c k h)$.

Since the three parameters are characterised by different physical meanings and orders of magnitude, their values are conveniently reclassified in three classes. The choice of a 


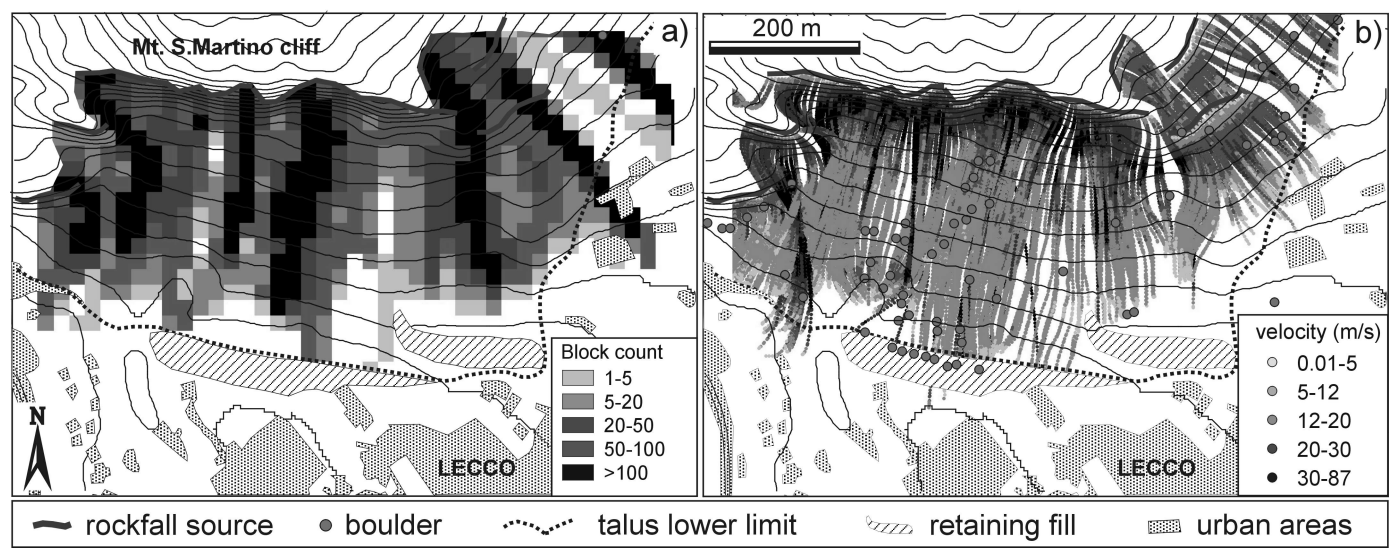

Fig. 4. Close up of the Mt. S. Martino cliff area (north of Lecco urban area). Model results obtained at different scale and data format are shown: (a) raster map of the rockfall count, obtained from the regional scale model of the Lecco Province (20 m ground resolution DEM); (b) vector trajectories, classified by velocity, obtained from the local-scale model of the Mt. S. -Coltignone area (5 m ground resolution DEM).

small number of classes allows us to simplify the classification and ranking of the computed RHI values (i.e. a 3 class subdivision results in 27 RHI values) and to obtain clearer hazard maps. The classification and ranking of the factors contributing to hazard is an intrinsically uncertain task, usually performed on a subjective basis. In order to overcome this problem at least partially, the three controlling parameters are classified according to standard criteria, established through the objective evaluation of the "potential destructiveness" of simulated rockfalls. Hazard assessment is usually performed for planning or mitigation purposes. From this point of view, an increasing kinetic energy implies higher capability of a falling rock of damaging structures (i.e. buildings, infrastructure, etc.) and passive countermeasures (e.g. barriers). In addition, higher maximum fly height results in higher probability for barriers to be overcome or for higher structures to be hit. According to these considerations, we decided to reclassify the parameters $c, k$ and $h$ according to a scheme (Table 1) directly related with the possible final use of hazard maps for mitigation purposes.

The range of computed values of translational kinetic energy $k$ is reclassified in three classes. Class intervals correspond to the maximum energy absorption capacity of common types of rockfall barriers, namely: elastic catch nets (absorbable energy up to $700 \mathrm{~kJ}$ ) and elasto-plastic barriers (absorbable energy up to $2500 \mathrm{~kJ}$ ). The basic idea is that more hazardous rockfalls are able to damage more effective barrier typologies. This also conveys in the final hazard map useful information for hazard reduction through countermeasure design. Thus, classes 1,2 and 3 will be defined for $0<k \leq 700 \mathrm{~kJ}, 700<k \leq 2500 \mathrm{~kJ}$ and $>2500 \mathrm{~kJ}$, respectively. In the last ten years, advances in material science and barrier technology has brought new barrier types, characterised by higher capacity. Nevertheless, we found that the proposed values are representative of the most used passive countermeasures in the Italian alpine area. In a similar way, rockfall fly height $h$ is reclassified according to the ability of a rockfall to overcome specific types of passive countermeasures, namely: catch nets $(h=4 \mathrm{~m})$ and retaining fills ( $h$ up to $10 \mathrm{~m})$. In this case classes 1,2 and 3 will be defined for $0<h \leq 4 \mathrm{~m}, 4<h \leq 10 \mathrm{~m}$ and $h>10 \mathrm{~m}$, respectively. The zero value for the parameter $h$ is included in the class 1 , differently from the kinetic energy. In fact, a value of $0 \mathrm{~kJ}$ means no rockfall occurrence (or a stopped rockfall), while a fly height of zero means that the block is impacting or rolling. Eventually, class limits for $k$ and $h$ can be redefined by users involved in rockfall analysis in different geomorphological or engineering settings and practice standard, if information concerning the existing structures (heights of buildings) and countermeasures (heights and capacities of barriers; Gerber, 2001) are available. Nevertheless, the reclassification criteria should be retained if this method is used.

The reclassification of the rockfall count is more difficult, since unique meaningful class boundaries in the rockfall count do not exist. In fact, the number of blocks passing through a model cell depends on the topography and the number of launched blocks, and strongly varies on a caseby-case basis. Thus, we propose to reclassify count values normalised according to two different approaches, depending on whether the modelling is performed at a regional or at a local scale (Table 1).

For regional scale models, characterised by a very large number of launched blocks (e.g. up to 1 million or more), the rockfall count is normalised by a specific approach. We know that most hazardous areas are associated to the maximum probability of rockfall occurrence, and that rockfall frequency on a channelled topography is significantly higher than that on simple planar slopes. Thus, rockfall count values can be normalised with respect to standard values representing the transition from planar to channelled morphologies. We assume that at least 5 "contributing" cells, located in a C-shaped pattern, are needed to initiate a channel effect on a given cell. This corresponds to the transition from a planar to a channelled morphology. A number of 5 contributing 
Table 2. Calibrated average values and variability ranges of the restitution and friction coefficients for the Lecco Province rockfall model. The different terrain classes have been obtained by "unique condition" combination of surface lithology and land use

\begin{tabular}{lllllll}
\hline Terrain class & $e_{n}$ & range & $e_{t}$ & range & $\tan (\Phi)$ & range \\
\hline Outcropping rock, forested & 0.50 & \pm 0.0100 & 0.70 & \pm 0.0140 & 0.55 & \pm 0.0110 \\
Outcropping rock, bare & 0.50 & \pm 0.0125 & 0.75 & \pm 0.0150 & 0.45 & \pm 0.0080 \\
Subcropping rock, forested & 0.40 & \pm 0.0080 & 0.65 & \pm 0.0130 & 0.55 & \pm 0.0110 \\
Subcropping rock, non forested & 0.45 & \pm 0.0090 & 0.70 & \pm 0.0140 & 0.50 & \pm 0.0100 \\
Glacial deposit, forested & 0.20 & \pm 0.0040 & 0.40 & \pm 0.0080 & 0.60 & \pm 0.0120 \\
Glacial deposit, non forested & 0.25 & \pm 0.0050 & 0.50 & \pm 0.0100 & 0.60 & \pm 0.0120 \\
Rockslide deposit, forested & 0.30 & \pm 0.0060 & 0.60 & \pm 0.0120 & 0.50 & \pm 0.0100 \\
Rockslide deposit, non forested & 0.30 & \pm 0.0060 & 0.65 & \pm 0.0130 & 0.45 & \pm 0.0080 \\
Cemented talus, forested & 0.35 & \pm 0.0070 & 0.60 & \pm 0.0120 & 0.55 & \pm 0.0110 \\
Cemented talus, bare & 0.35 & \pm 0.0070 & 0.70 & \pm 0.0140 & 0.45 & \pm 0.0080 \\
Talus, forested & 0.30 & \pm 0.0060 & 0.60 & \pm 0.0120 & 0.50 & \pm 0.0100 \\
Talus, bush covered & 0.33 & \pm 0.0175 & 0.63 & \pm 0.0126 & 0.55 & \pm 0.0110 \\
Talus, bare & 0.35 & \pm 0.0066 & 0.65 & \pm 0.0130 & 0.60 & \pm 0.0120 \\
Lacustrine and peat deposit, forested & 0.20 & \pm 0.0040 & 0.40 & \pm 0.0080 & 0.65 & \pm 0.0130 \\
Lacustrine and peat deposit, non forested & 0.25 & \pm 0.0050 & 0.55 & \pm 0.0110 & 0.70 & \pm 0.0140 \\
Alluvial deposit, forested & 0.25 & \pm 0.0050 & 0.55 & \pm 0.0110 & 0.65 & \pm 0.0130 \\
Alluvial deposit, non forested & 0.25 & \pm 0.0050 & 0.60 & \pm 0.0120 & 0.60 & \pm 0.0120 \\
Colluvial deposit, forested & 0.25 & \pm 0.0050 & 0.50 & \pm 0.0100 & 0.65 & \pm 0.0130 \\
Colluvial deposit, non forested & 0.25 & \pm 0.0050 & 0.65 & \pm 0.0130 & 0.60 & \pm 0.0120 \\
\hline
\end{tabular}

cells is a lower bound value for channelling, assuming that other contributing cells (e.g. from rockfall sources placed above on the slope) are ignored. According to this approach, the rockfall count $(c)$ at any given transit cell is normalised with respect to the number $(5 * n)$ of launched blocks from each group of 5 contributing source cells ( $n$ is the number of blocks launched from each cell). Thus, for the transition from planar to channelled slopes (5 contributing cells) and, for example, for $n=1$, the count is $c=5$ and the normalised count value will be $c /(5 * n)=1$. On the opposite, for a rectilinear source area corresponding to a planar slope ( 1 contributing cell), for $n=1$ the count is $c=1$ and the normalised count will be $c /(5 * n)=0.2$. This approach allows to normalise the count by describing implicitly also the relative size of the contributing area. Normalised count values less than 0.2 will denote low rockfall frequency in unchannelled areas. Values ranging from 0.2 to 1 will denote increasing rockfall frequency on relatively simple slopes. Finally, values higher than 1 will identify the most hazardous areas with respect to rockfall frequency (e.g. areas characterised by convergence of trajectories or very high rockfall frequency on planar slopes). The approach provides a way to reclassify the count independent on the actual count value, which can be a weak indicator itself.

For local scale models, where the geomechanical features of localised source areas are better known, we normalised the rockfall count with respect to the total number of launched blocks from a single homogeneous area (i.e. characterised by uniform size, mass and frequency of launched blocks). The two main reasons for this different approach are, namely: the need to compare the different hazard deriving from blocks falling from homogeneous areas; the importance of maintaining separate the contributions given by blocks coming from different source areas but converging on the same invasion area. When homogeneous sub-areas are not defined, the rockfall count can be normalised according to the same criterion used at regional scale. For the local scale models, we propose to reclassify the normalised count values according to the following intervals: $<0.01,0.01-0.1,>0.1$. We stress in any case the fact that different intervals can be chosen according to model outputs and the number of launched blocks.

Once the input parameters have been reclassified (Table 1), they are combined to obtain a value of the 3-digit positional Rockfall Hazard Index (RHI), portraying on the map a specific level of hazard and retaining in each digit the information about the contribution of each parameter. The resulting 27 classes (Fig. 2a and b) are considered sufficient to represent hazard but they are not easily represented in a map. Then, further regrouping is performed to result in 3 hazard classes (low, intermediate and high). This requires a ranking criterion allowing us to translate the positional index value into a sequential value. Such a criterion is provided by the magnitude of a Rockfall Hazard Vector ( $\boldsymbol{R} \boldsymbol{H} \boldsymbol{V})$ (Fig. 2c), defined as:

$\boldsymbol{R} \boldsymbol{H} \boldsymbol{V}=\left(\begin{array}{l}c \\ k \\ h\end{array}\right)$,

where $c, k$ and $h$ are the reclassified values of the input parameters (i.e. RHI digits). The $\boldsymbol{R} \boldsymbol{H} \boldsymbol{V}$ magnitude is simply 
Table 3. Calibrated average values and variability ranges of the restitution and friction coefficients for the Mt. S. Martino-Coltignone area rockfall model. The different terrain classes have been obtained by "unique condition" combination of surface lithology and land use

\begin{tabular}{lllllll}
\hline Terrain class & $e_{n}$ & range & $e_{t}$ & range & $\tan (\Phi)$ & range \\
\hline Outcropping limestone, forested & 0.60 & \pm 0.0300 & 0.75 & \pm 0.0375 & 0.50 & \pm 0.0250 \\
Outcropping limestone, bare & 0.65 & \pm 0.0325 & 0.85 & \pm 0.0425 & 0.40 & \pm 0.0200 \\
Subcropping limestone, forested & 0.50 & \pm 0.0250 & 0.60 & \pm 0.0300 & 0.55 & \pm 0.0200 \\
Subcropping limestone, non forested & 0.60 & \pm 0.0300 & 0.75 & \pm 0.0375 & 0.40 & \pm 0.0275 \\
Glaciofluvial deposit, forested & 0.30 & \pm 0.0150 & 0.65 & \pm 0.0325 & 0.75 & \pm 0.0375 \\
Glaciofluvial deposit, non forested & 0.30 & \pm 0.0150 & 0.70 & \pm 0.0350 & 0.60 & \pm 0.0300 \\
Glacial deposit, forested & 0.25 & \pm 0.0125 & 0.55 & \pm 0.0275 & 0.70 & \pm 0.0350 \\
Glacial deposit, non forested & 0.25 & \pm 0.0125 & 0.65 & \pm 0.0325 & 0.65 & \pm 0.0325 \\
Talus, forested & 0.35 & \pm 0.0175 & 0.70 & \pm 0.0350 & 0.55 & \pm 0.0275 \\
Talus, bush covered & 0.35 & \pm 0.0175 & 0.75 & \pm 0.0375 & 0.50 & \pm 0.0250 \\
Talus, bare & 0.35 & \pm 0.0175 & 0.70 & \pm 0.0350 & 0.65 & \pm 0.0325 \\
Cemented talus, forested & 0.45 & \pm 0.0225 & 0.65 & \pm 0.0325 & 0.50 & \pm 0.0250 \\
Cemented talus, bare & 0.50 & \pm 0.0250 & 0.70 & \pm 0.0350 & 0.45 & \pm 0.0225 \\
\hline
\end{tabular}

given by:

$$
|\boldsymbol{R} \boldsymbol{H} \boldsymbol{V}|=\sqrt{c^{2}+k^{2}+h^{2}} .
$$

Since $c, k$ and $h$ are discrete, the vector magnitude is discrete, too. Nevertheless, the magnitude of the $\boldsymbol{R} \boldsymbol{H} \boldsymbol{V}$ vector allows us to rank the hazard level in classes and to obtain an objective and clear hazard map.

\section{Example applications}

The Rockfall Hazard Index/Vector method has been tested at different scales in two study areas in the Central Italian Alps (Lombardy, Northern Italy), namely: the Lecco Province and the Mt. S. Martino-Coltignone area (Fig. 3). For the former we performed a regional hazard assessment, whereas for the latter we ascertained rockfall hazard at the local scale.

4.1 Regional scale modelling: the Lecco Province (Lombardia Region, Northern Italy)

The Lecco Province covers about $570 \mathrm{~km}^{2}$, mainly along the eastern shore of Como Lake (Fig. 3). Thinly bedded and massive limestone, dolostone, marl, sandstone and metamorphic rocks (Crosta, et al., 2001) crop out. In this area, high and very steep rock slopes are frequent especially in limestone and dolostone. Rockfalls are also frequent, posing a severe threat to some urban areas and along roads and the railway running along Como Lake. Fatalities caused by rockfalls (Cancelli and Crosta, 1993; Crosta and Locatelli, 1999; Agostoni et al., 1999) have occurred in the area of Mt. S. Martino-Coltignone (February 1969, 8 casualties), at Valmadrera (July 1981, 1 casualty), at Onno Lario (1984, 1 casualty) and at Varenna (May 1997, 5 casualties).

A DEM with a ground resolution of $20 \mathrm{~m}$ was available for the entire area, obtained by interpolation of a subset of contour lines from the 1:10000 scale topographic maps of the
Regione Lombardia. The source areas of rockfalls were ascertained from a landslide inventory map prepared by the Regione Lombardia and the Province of Lecco (Agostoni et al., 1999). About $57 \mathrm{~km}^{2}$ of the whole territory (10\% of the total area) have been mapped as a possible "source area of rockfalls". These areas include rocky cliffs identified on 1:10000 topographic maps and from stereoscopic aerial photos. Minor unstable rock outcrops have been mapped through field surveys and historical rockfall reports, and 141385 source cells were identified at the same ground resolution of the DEM. Since the experimental determination of the restitution (normal and tangential) and dynamic rolling friction coefficients across large areas is impossible both for logistic and budget limitations, initial values for such coefficients were attributed by reclassifying a "unique condition map" obtained by overlaying information about surface lithology, slope deposits, landslides, and vegetation, in order to obtain homogeneous "land units" with respect to the restitution and friction characteristics. As a consequence, unique condition areas are sectors of the study area where different features (i.e. lithology, slope deposits, landslides, vegetation, land use, etc.) are present with the same attribute (e.g. limestone, blocks, no landslide, grass, pasture, etc.).

Table 2 shows the classes adopted in the unique condition map, and the relative average calibrated values for the normal, tangential and rolling friction coefficients. Initial selection of the coefficients was based on data available in the literature (Crosta and Agliardi, 2000) for the same type of simulation approach. The range of values for each unique condition class has been calibrated according to the extension of scree slopes, to historic rockfall events and to the location of major boulders along the slopes. This was the most time demanding phase of the whole study because of its significance on the final results (Agliardi and Crosta, 2002).

Rockfall modelling has been performed using a probabilistic approach, by throwing 10 blocks from each source cell (for a total of 1413850 launched blocks) and allowing for the 


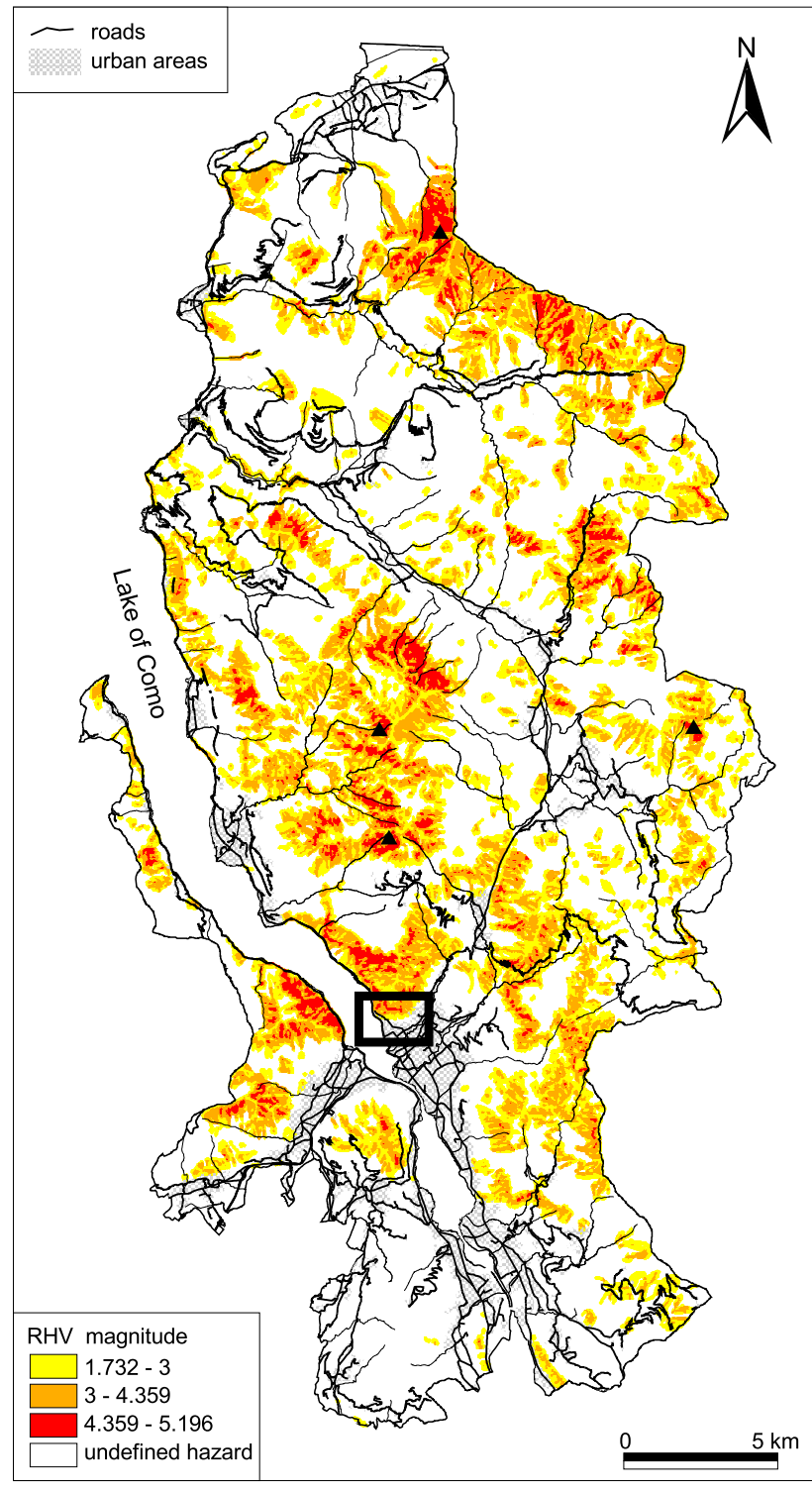

Fig. 5. Regional rockfall hazard map for the Lecco Province $\left(570 \mathrm{~km}^{2}\right)$. The low resolution of the rockfall model allows for a preliminary recognition of hazard.

variability of restitution and friction coefficients into specified ranges. Cells exhibiting a very large rockfall count are located mostly along channels or in areas where the topography concentrates the falling blocks. The maximum computed velocities and heights reach $100 \mathrm{~m} / \mathrm{s}$ and $500 \mathrm{~m}$, respectively. A map of the translational kinetic energy, to be reclassified for hazard assessment, has been computed by considering a constant block size of $3 \mathrm{~m}^{3}$, corresponding to about $8000 \mathrm{~kg}$, i.e. a representative size for damaging blocks in the area. Model results indicate that 328342 cells, corresponding to about $131 \mathrm{~km}^{2},(23 \%$ of the study area), are prone to rockfalls. Figure 4 a shows a close-up of the computed rockfall count in the Mt. S. Martino cliff area (northern part of the Lecco urban area). The regional scale model is useful for large-scale, recognition rockfall analysis and hazard assessment, but not suitable for site-specific engineering purposes (Agliardi and Crosta, 2002).

\subsection{Local-scale assessment: the Mt. S. Martino-Coltignone area}

The Mt. S.-Coltignone area is located north of the city of Lecco and south of the Grigne Massif (Fig. 3). In this area, limestone cliffs up to $400 \mathrm{~m}$ high impend directly on some suburbs of Lecco and on the State Road 36, an important transportation corridor connecting the southern Lombardia to Switzerland and Valtellina. The area has been historically prone to rockfalls (e.g. 1931, 2 casualties; 1935; 1950; 1952; 1955 , a house destroyed; $1962 ; 1965 ; 1969 ; 1970 ; 1983$, about $4000 \mathrm{~m}^{3}$ involved; 1994; 1995; 1996). The most severe event occurred on 22 February 1969 when a $15000 \mathrm{~m}^{3}$ rockfall destroyed 2 houses and killed 7 people. After the 1969 rockfall, extensive defensive countermeasures were built, including several orders of large elastic fences (total length of about $8 \mathrm{~km}$ ) and a retaining wall $10 \mathrm{~m}$ high (Broili, 1973).

A detailed DEM has been specifically prepared for the Mt. S. Martino area at a ground resolution of $5 \mathrm{~m}$ by digitising and interpolating contour lines at $5 \mathrm{~m}$ intervals from a 1:5000 scale raster topographic map. The analysis of large scale multi-temporal aerial stereo-photos $(1954,1962$ and $1974 \mathrm{~b} / \mathrm{w}, 1981$ color) and ortho-photos (1994 b/w, 2000 color) allowed us to identify the main geomorphological and structural features, the active rocky cliffs and rockfall sources, the land use and vegetation. Field surveys allowed us to validate these data, to collect detailed information for modelling and to assess the geomechanical characteristics of the rock mass. Four joint sets and bedding have been recognised, separating blocks ranging in volume between $0.35 \mathrm{~m}^{3}$ and $3.2 \mathrm{~m}^{3}$, with an average value of about $1 \mathrm{~m}^{3}$. Plane and wedge failure, block toppling and tensile failure proved to be kinematically feasible processes.

A total of 717, $5 \times 5 \mathrm{~m}$ source cells were identified, corresponding to about $0.9 \%$ of the study area). As for the regional scale study, the restitution and friction coefficients were obtained by merging and reclassifying in a GIS geology, surface geology and land use maps, specifically prepared by the authors for this study at the same scale as the topographic data. Table 3 shows the 13 classes in the unique condition map, and the calibrated average values the relevant coefficients. Since detailed geomechanical information was available, the source areas have been subdivided in homogeneous domains with respect to their geomechanical susceptibility to failure. Six major domains have been outlined, depending on the block size (minimum, average, maximum) and the frequency of detachment. This subdivision has been fundamental to give a hazard zonation in terms of block mass or energy and to include in the analysis the relative susceptibility to rockfalls, a proxy for the onset probability.

Several simulations have been run using DEMs at different ground resolutions. The original $5 \mathrm{~m}$ DEM has been resampled at $10 \mathrm{~m}$ and $20 \mathrm{~m}$, respectively, in order to eval- 


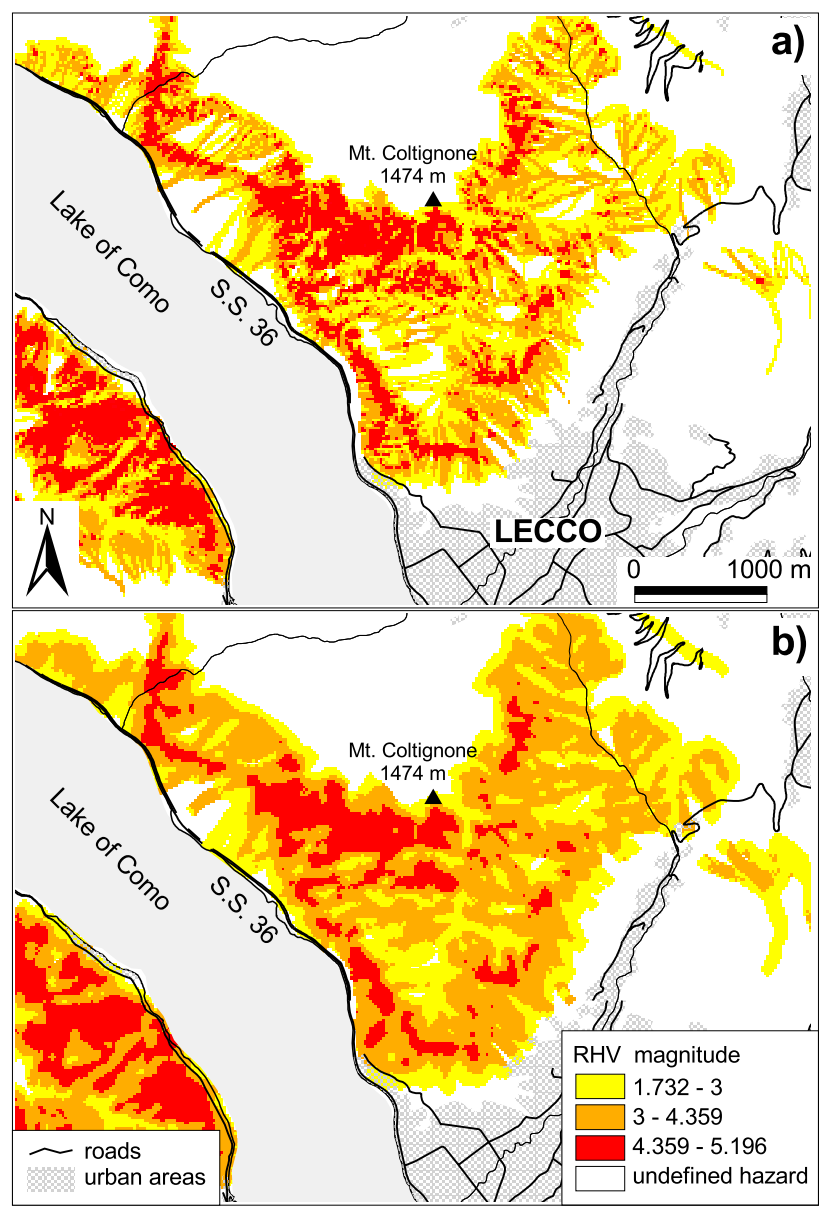

Fig. 6. Close-up of the regional scale Lecco Province model $(20 \mathrm{~m}$ ground resolution): (a) raw hazard map obtained by the application of the procedure, classified by the $\boldsymbol{R} \boldsymbol{H} \boldsymbol{V}$ magnitude; (b) "smoothed" hazard map obtained by averaging neighbouring cells through spatial statistics techniques. See text for explanation.

uate the effect of spatial resolution on the resulting hazard maps. Models have been run with a probabilistic approach, by launching a different number of blocks from each homogeneous source areas. Model calibration has been performed by comparing the results to the extent of talus slopes, the location of observed blocks, and the runout recorded for the reported historical events (from a few to some hundreds of cubic metres). Different maps of the translational kinetic energy have been computed using fixed block masses for the entire model, namely: $1000 \mathrm{~kg}, 2700 \mathrm{~kg}$ and $8600 \mathrm{~kg}$, corresponding to the minimum, average and maximum block size detected in the entire area, respectively. In addition, a set of kinetic energy maps has been calculated using the maximum, average and minimum block mass value typical of each recognised homogeneous area.

According to the model, the total area exposed to rockfall hazard amounts to about $33 \%\left(681150 \mathrm{~m}^{2}\right)$ of the model area $\left(2043125 \mathrm{~m}^{2}\right)$. Areas exposed to the transit of more than 1 and 5 blocks amount to about the $30 \%\left(624650 \mathrm{~m}^{2}\right)$ and $18 \%\left(372225 \mathrm{~m}^{2}\right)$, respectively. Calibration of the
Table 4. Percentage of elements at risk, belonging to a given category, potentially affected by rockfalls in the Lecco Province

\begin{tabular}{cccc}
\hline $\begin{array}{c}\text { element at risk } \\
-\end{array}$ & $\begin{array}{c}\text { dimension } \\
-\end{array}$ & extent & $\begin{array}{c}\text { damaged } \\
\%\end{array}$ \\
\hline urban areas & {$\left[\mathrm{L}^{2}\right]$} & $73 \mathrm{~km}^{2}$ & 0.7 \\
Roads & {$[\mathrm{L}]$} & $667 \mathrm{~km}$ & 8.5 \\
railway tracks & {$[\mathrm{L}]$} & $5 \mathrm{~km}$ & 10.0 \\
\hline
\end{tabular}

model has been performed through the above mentioned approach. $72 \%$ of the mapped large blocks and $67 \%$ of the total talus areas are located within sectors affected by computed rockfall trajectories. Figure $4 \mathrm{~b}$ details the local scale model outputs. Rockfall trajectories in vector (point) format are portrayed, showing the high degree of detail of the simulation performed at $5 \mathrm{~m}$ ground resolution.

\subsection{Implementation and evaluation of hazard models}

The Rockfall Hazard Index/Vector procedure has been applied to the Lecco Province area and the Mt. S. MartinoColtignone area to obtain different sets of physically-based hazard maps for local end-users and to evaluate their effectiveness.

For the Lecco Province area, the results of low resolution modelling have been employed to obtain a preliminary recognition hazard map. Model results provided by STONE in raster format provide a conservative "worst case scenario" of hazard across an area of $570 \mathrm{~km}^{2}$. The final map (Fig. 5) has been classified according to the computed magnitude of the Rockfall Hazard Vector $(\boldsymbol{R} \boldsymbol{H} \boldsymbol{V})$ into three classes, namely: $1.732 \leq|\boldsymbol{R} \boldsymbol{H} \boldsymbol{V}| \leq 3$ (low rockfall hazard), $3<|\boldsymbol{R} \boldsymbol{H} \boldsymbol{V}| \leq 4.359$ (intermediate rockfall hazard) and $4.359<|\boldsymbol{R} \boldsymbol{H} \boldsymbol{V}| \leq 5.196$ (high rockfall hazard). A fourth class has been defined representing "undefined hazard" in areas where the rockfalls are not likely to occur according to the results of numerical modelling. It must be noted that, whereas the reclassification of the parameters contributing to hazard is performed according to objective criteria, a unique way to classify the level of hazard portrayed in the final map cannot be identified, since an objective definition of "low", "moderate" or "high" hazard by means of the $\boldsymbol{R} \boldsymbol{H} \boldsymbol{V}$ magnitude doesn't exist. Thus, the final classification of hazard has been calibrated using available information about documented rockfall events causing fatalities and damage to infrastructures and lifelines (S. Martino, 1969; Valmadrera, 1981; Onno Lario, 1984; Varenna, 1997, etc.) and geomorphological data. In addition, hazard classification should be calibrated according to the aim of the hazard assessments (landplaning, regulation or mitigation), the spatial scale of analysis and the frequency and worth of the elements at risk.

The hazard map obtained at a regional scale (Fig. 5) is useful to outline the areas more prone to rockfall. These areas are then selected for further local scale analyses taking 


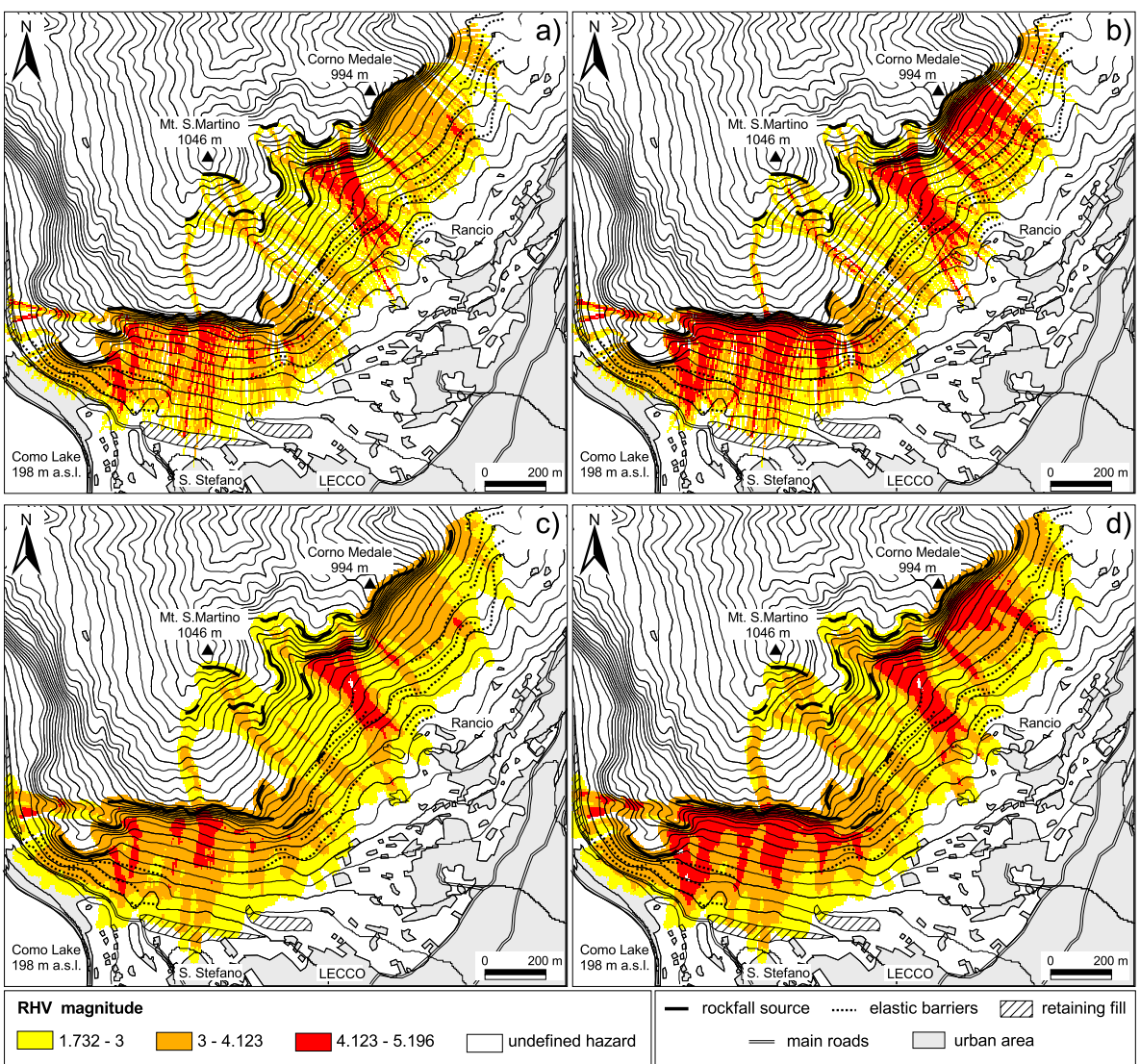

Fig. 7. Hazard maps obtained from the local-scale Mt. S. Martino-Coltignone model (at $5 \mathrm{~m}$ resolution). Hazard scenarios obtained by raster outputs using: (a) mean block mass, (b) maximum block mass. Smoothed maps by averaging $\boldsymbol{R} \boldsymbol{H} \boldsymbol{V}$ values through a $15 \mathrm{~m}$ radius neighbourhood analysis for: (c) mean block mass, (d) maximum block mass. Hazard is classified according to the $\boldsymbol{R} \boldsymbol{H} \boldsymbol{V}$ magnitude.

in account the distribution and types of different elements at risk. Due to the scale of analysis, the "raw" hazard map resulting from the application of the assessment procedure (Fig. 5) can be excessively fragmented for practical applications. Thus, spatially distributed statistical techniques have been employed in order to obtain a smoother hazard zonation. The "raw" hazard map has been smoothed by averaging the $\boldsymbol{R} \boldsymbol{H} \boldsymbol{V}$ magnitude value at each cell with respect to the neighbouring cells within a radius of $20 \mathrm{~m}$. Figure 6 is a close-up of the regional scale hazard model for the area north of Lecco. It clearly shows that the smoothed hazard map is much less fragmented than the "raw" one, resulting in a more effective zonation.

The regional scale hazard model also allows for the preliminary evaluation of rockfall risk in the entire Lecco Province, with respect to different involved elements. A rigorous risk analysis, including the assessment of the vulnerability, worth and exposure of the elements at risk (Crosta et al., 2001) is beyond the scope of this paper. We simply evaluated the percentage of elements at risk, belonging to a given category, potentially affected by rockfalls, by assuming a unit (maximum) value for exposure. As shown in Table 4, only $0.7 \%$ of urbanised areas can be affected by rockfalls, whereas $10 \%$ of the roads and $8.5 \%$ of the railway tracks are

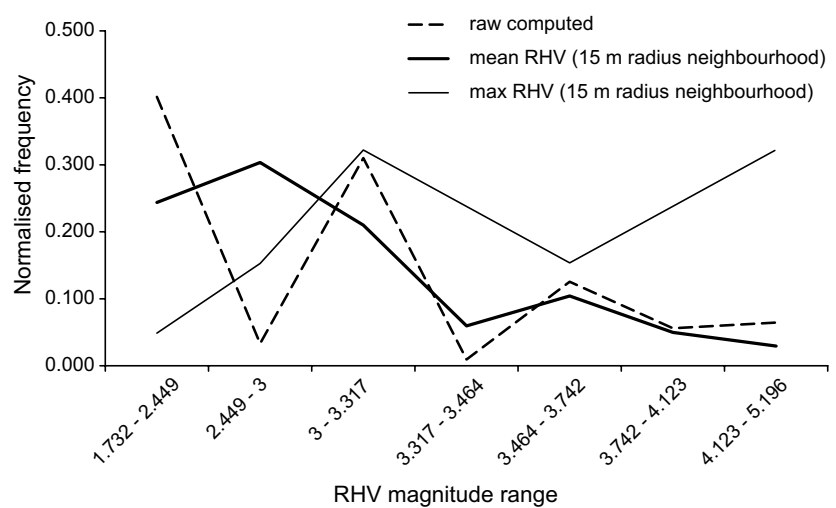

Fig. 8. Plot of the normalised areal frequency of $\boldsymbol{R} \boldsymbol{H} \boldsymbol{V}$ classes for different source hazard maps: raw $\boldsymbol{R} \boldsymbol{H} \boldsymbol{V}$ values, smoothed mean and maximum $\boldsymbol{R} \boldsymbol{H} \boldsymbol{V}$ values.

prone to be damage, especially along the main transportation corridor (State Road 36 and the Lecco-Sondrio railway track) to the northern Lombardia. This evaluation is not exhaustive for risk assessment purposes, but provides a first estimate of the most prone elements at risk and their location.

For the Mt. S. Martino-Coltignone area (Fig. 7), local scale 

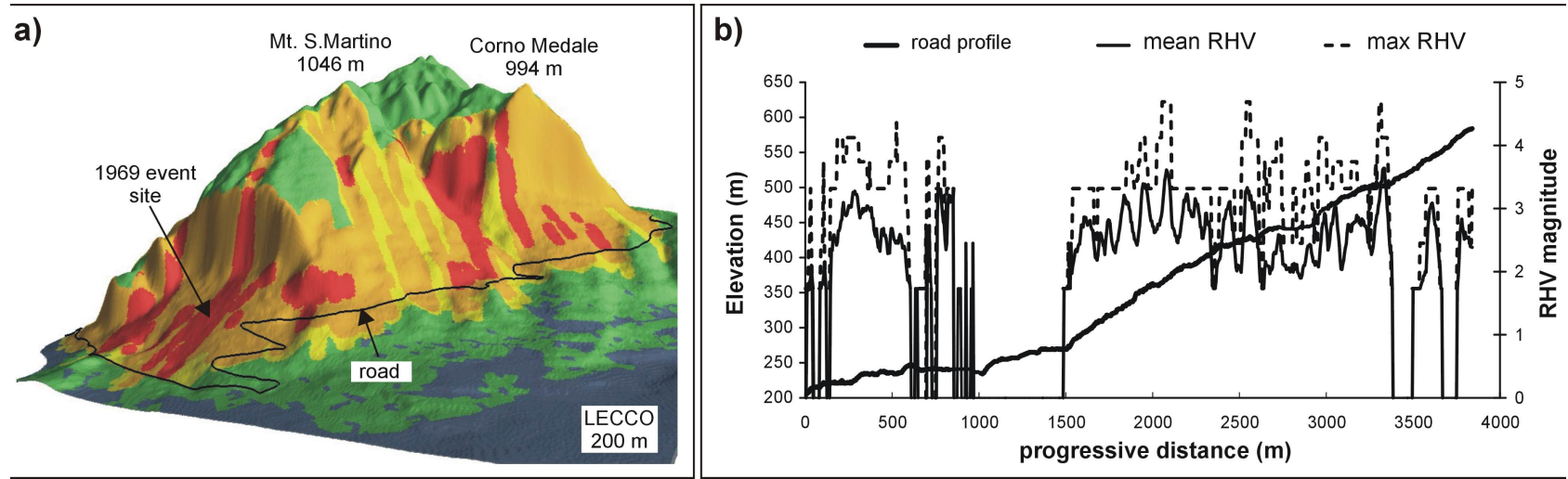

Fig. 9. Example of distributed hazard assessment along linear features: (a) 3-D representation of the hazard map for the Mt. S. MartinoColtignone area with the analysed road path, (b) plot of the computed $\boldsymbol{R} \boldsymbol{H} \boldsymbol{V}$ values (smoothed by the mean and the maximum values in the neighbourhood) along the road profile.

rockfall models performed at a ground resolution of $5 \mathrm{~m}$ on a small area (about $3 \mathrm{~km}^{2}$ ) allowed us to obtain hazard maps suitable for planning and mitigation at the Lecco municipality scale. Geomechanical characterisation of the involved rock masses (not presented here in detail) allowed us to consider different onset probabilities and block masses for each outlined homogeneous domain. By considering the statistical distribution of block masses detected in different areas, different hazard maps have been produced, including in the hazard assessment kinetic energies corresponding to the mean and maximum block masses.

Also for the Mt. S. Martino-Coltignone area, the hazard maps have been classified according to the computed magnitude of the Rockfall Hazard Vector $(\boldsymbol{R} \boldsymbol{H} \boldsymbol{V})$. In this case, the three hazard classes have been defined as: $1.732 \leq$ $|\boldsymbol{R} \boldsymbol{H} \boldsymbol{V}| \leq 3$ (low hazard), $3<|\boldsymbol{R} \boldsymbol{H} \boldsymbol{V}| \leq 4.123$ (intermediate hazard) and $4.123<|\boldsymbol{R} \boldsymbol{H} \boldsymbol{V}| \leq 5.196$ (high hazard). Class boundaries have been calibrated in detail using the record of historical events affecting the area in the last four decades. The resulting maps have been smoothed using a similar approach to that used for the regional scale hazard model to produce a more readable, less fragmented hazard map (Figs. 7c and d). Smoothing was done by neighbourhood analysis within a radius of $15 \mathrm{~m}$.

Smoothing the computed hazard maps through neighbourhood statistics techniques could eventually lead to unrealistic hazard scenarios, i.e. smoothing operations could result in too conservative or optimistic hazard maps, depending on the employed statistics. In Fig. 8, we plot the areal frequency (normalised by the total area prone to rockfalls) of different $\boldsymbol{R} \boldsymbol{H} \boldsymbol{V}$ values for the "raw" computed hazard map and the smoothed hazard maps. The smoothing has been performed by computing the mean or maximum values in the neighbourhood analysis (radius of $15 \mathrm{~m}$ ). The use of mean values from the neighbourhood analysis results in a more conservative hazard map. Largest deviations of the smoothed $\boldsymbol{R} \boldsymbol{H} \boldsymbol{V}$ values from the raw computed ones occur for the "Flow hazard" cells (Fig. 8), whereas the number of "high hazard" cells re- mains substantially unchanged. In addition, a redistribution of "high hazard" cells can be observed: areas characterised by high hazard become more continuous, while meaningless isolated "high hazard" pixels disappear. Thus, hazard maps smoothed by the mean $\boldsymbol{R} \boldsymbol{H} \boldsymbol{V}$ values are regarded to be representative of the computed hazard scenario and suitable as planning tools. On the contrary, hazard maps smoothed by using the maximum $\boldsymbol{R} \boldsymbol{H} \boldsymbol{V}$ in the neighbourhood result in unacceptably high hazard ratings, that are not feasible for practical assessment purposes.

Maps obtained through the proposed procedure can be employed for hazard assessment along linear features (transportation corridors, lifelines, etc.). We report an example of rockfall hazard assessment for a road running along the toe of the Mt. S. Martino-Corno Medale slopes (Fig. 9a). The $\boldsymbol{R} \boldsymbol{H} \boldsymbol{V}$ magnitude values have been sampled from the smoothed hazard maps along the the road (Fig. 9a). The values are plotted versus the progressive distance (Fig. 9b), from the lower to the maximum elevation. $\boldsymbol{R} \boldsymbol{H} \boldsymbol{V}$ values sampled every $5 \mathrm{~m}$ from previously smoothed hazard maps have been used for the evaluation of the most hazardous sectors along the road. This results could be useful to optimise maintenance and remediation works.

The highly detailed analysis at local scale allowed us to evaluate the sensitivity of hazard maps to the input parameters, their format (raster/vector) and spatial resolution. This leads to a more objective choice of the "best" hazard map with respect to the quality of the data and to the modelling approach. Different hazard maps has been obtained by using raster modelling outputs and by employing different masses, namely: $1000 \mathrm{~kg}$ (fixed for the entire model), and the mean and maximum masses for each of the homogeneous geomechanical domains (Fig. 7). The same analysis has been performed at different spatial resolution, namely: $5 \mathrm{~m}, 10 \mathrm{~m}$ and $20 \mathrm{~m}$, using resampled DEMs (Fig. 10). The resulting hazard maps have been compared by means of diagrams portraying the areal frequency (normalised by the total area prone to rockfalls) of the different $\boldsymbol{R} \boldsymbol{H} \boldsymbol{V}$ magnitude values (Fig. 11). 

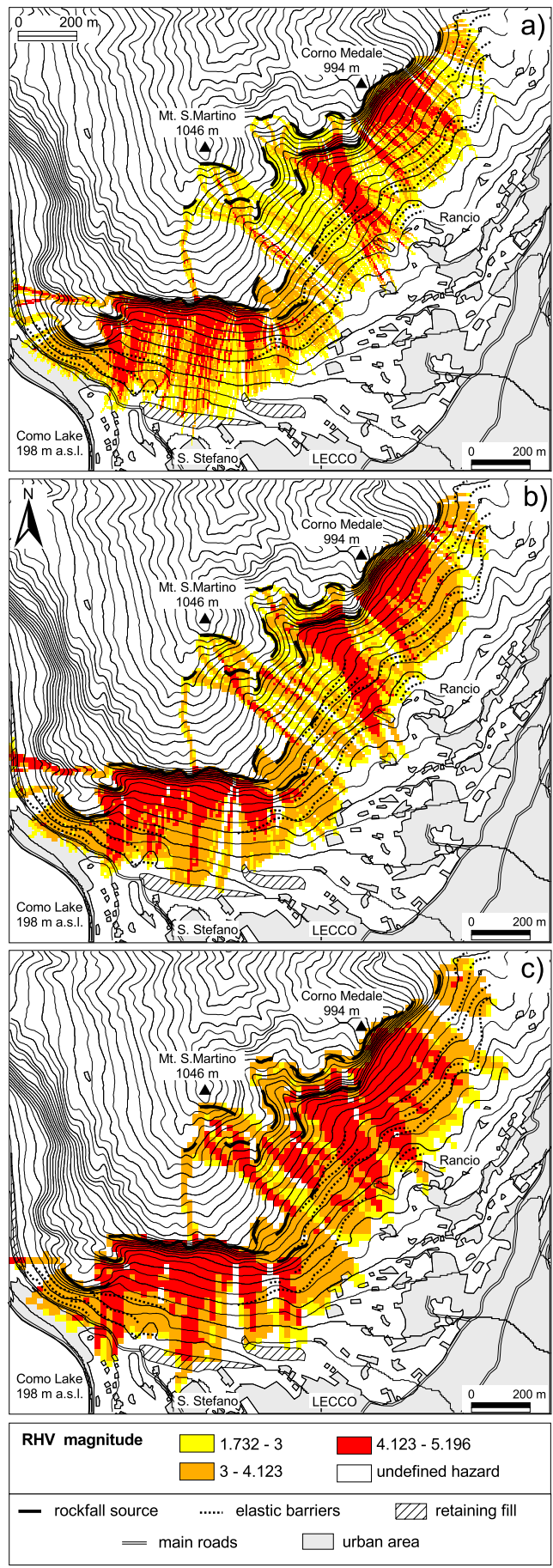

Fig. 10. Comparison of the hazard maps obtained for the Mt. S. Martino-Coltignone area at different spatial resolution $(5 \mathrm{~m}$, $10 \mathrm{~m}$ and $20 \mathrm{~m}$, respectively). Model raster outputs and a constant block mass have been employed.

We observe that:

- at any spatial resolution (Figs. 11a, b and c), an increase of the block mass results in increasingly hazardous maps. This effect is more important when the maximum mass is used. This is obvious, since an in- crease of the input mass results in increased computed kinetic energy;

- the number of high hazard cells increases (Figs. 11d, e and f) for decreasing model resolution. This can be related to the higher velocities computed for low resolution models, which increase the computed kinetic energy (Agliardi and Crosta, 2002; Agliardi and Crosta, 2003);

- the shift toward higher hazard levels, as block mass increases, is more relevant for lower resolution models. This results from the combination of two factors contributing to hazard by increasing the kinetic energy, namely: larger mass (input) and higher velocity (computed for lower resolutions).

The aforementioned observations stress the importance of collecting accurate geomechanical and topographic data. The frequency distribution of block size for a homogeneous source area is required in order to introduce onset probability and to choose among different modelling approaches. The mean observed mass can be used to represent the most common hazard scenario. The maximum mass can be used if more conservative results are needed when highly populated areas or extremely valuable elements at risk are involved. It is worthwhile to recall that the raster outputs of the program STONE are themselves conservative, since they represent the worst kinematic conditions. Thus, they are suitable for regional scale analyses, whereas, at local scales, vector outputs should be used. In fact, they provide local kinematic information allowing for more accurate hazard assessment (Fig. 12) and for a better compromise between safety and urban development.

\section{Concluding remarks}

Spatially distributed assessment of rockfall hazard is a difficult, intrinsically uncertain operation. The proposed methodology is based on the numerical modelling of rockfall trajectories, performed with a spatially distributed, threedimensional rockfall simulation program (Agliardi et al., 2001; Guzzetti et al., 2002). The Rockfall Hazard In$\mathrm{dex} /$ Vector assessment procedure is mainly focused on the propagation phase of rockfalls, which is responsible of most of the uncertainty affecting the analysis. The onset (or triggering) probability is to be independently evaluated prior to the modelling phase, by geomechanical and/or probabilistic analyses, whose discussion is beyond the aim of this paper. The onset probability is introduced in the simulations through the number of launched blocks from different source areas, affecting the rockfall occurrence probability at a given location to which simulated rockfalls propagate.

The proposed hazard assessment procedure minimizes subjectivity in the choice of the criteria used to reclassify the involved parameters. We propose the Rockfall Hazard Vector to overcome the ambiguity in hazard ranking allowing a direct and objective hazard zonation. If this is accepted, 

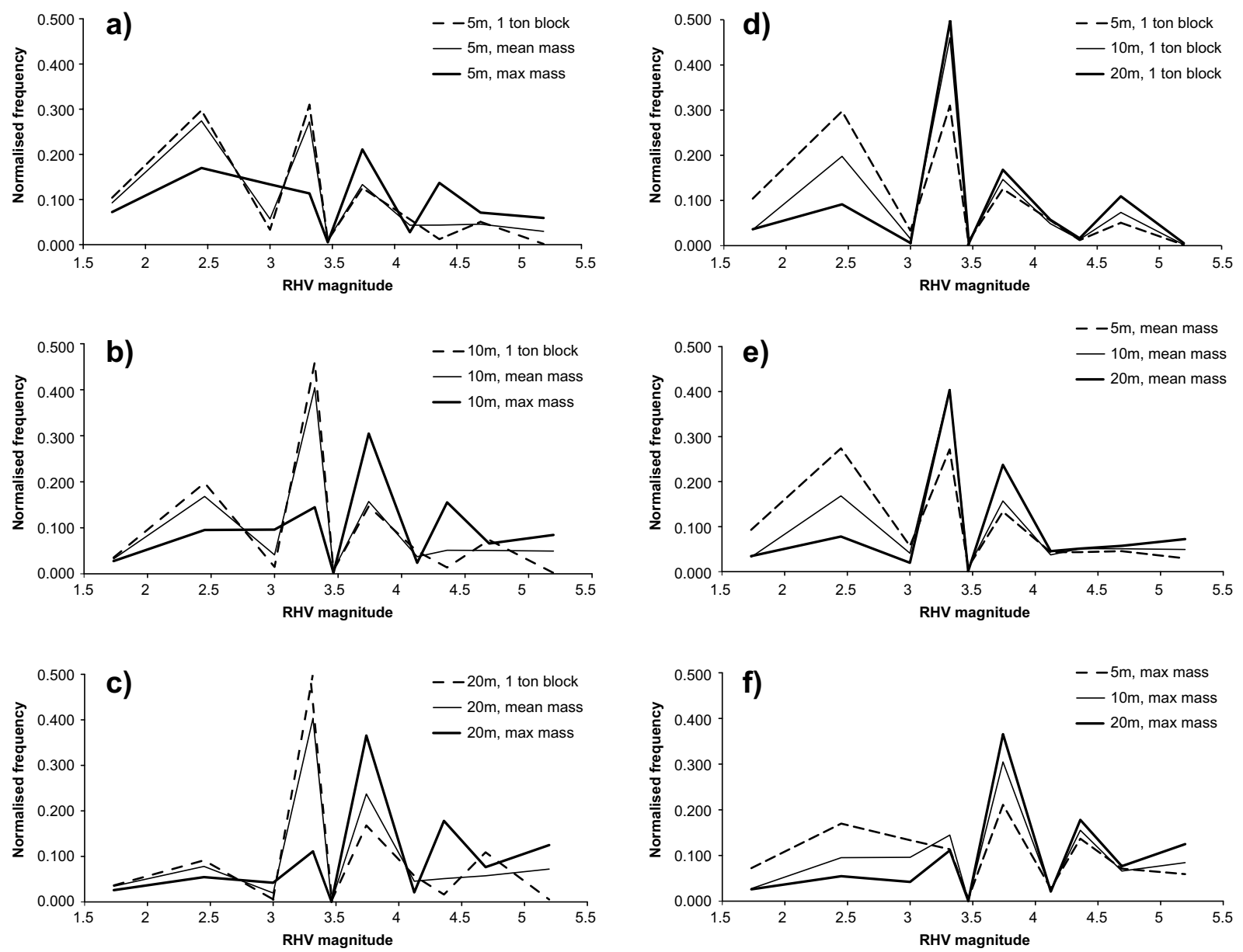

Fig. 11. Quantitative comparison of the different hazard maps obtained for the Mt. S. Martino-Coltignone area with different combinations of block mass and spatial resolution. Diagrams portray the areal frequency of the different values of $\boldsymbol{R} \boldsymbol{H} \boldsymbol{V}$ magnitude.

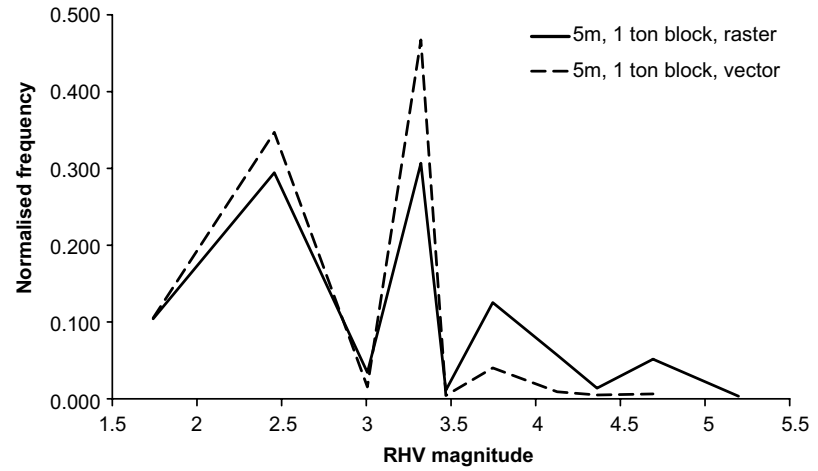

Fig. 12. Comparison between hazard models with same resolution ( $5 \mathrm{~m}$ ) and block mass ( 1 ton), but employing vector and raster model outputs.

the users only need to concentrate their attention on the construction of reliable rockfall numerical models. Nevertheless, different types of hazard problems (i.e. point-like, linear and areal problems) require different definitions for the occurrence probability and intensity. Thus, different ver- sions of the method could be implemented and modified to be suitably applied to different problems. To improve the method and to refine existing empirical and semi-empirical approaches, the results obtained by using the method will be compared to existing hazard assessment methodologies (Cancelli and Crosta, 1993; Rouiller and Marro, 1997; Crosta and Locatelli, 1999). Applications of the modelling approach to the planning and design of countermeasures by including hazard values is currently under development.

The method will be further developed to be used in different "rockfall settings" and to provide guidelines for the evaluation of hazard map quality to be adopted by regional and local administrations in charge of the public safety and land planning.

Acknowledgements. The authors are grateful to R. Detti for computer programming, and to M. Marian for his invaluable help in the preparation of the DEM of the Mt. S. Martino and in the testing of the hazard assessment procedure. F. Guzzetti is thanked for the continuous and clarifying discussions on the hazard assessment techniques. D. Fossati and M. Ceriani are thanked for providing useful criticisms. The research was carried in the framework of the EC DAMOCLES project (UE EVG1-CT-1999-00007 grant). 


\section{References}

Agliardi, F., and Crosta, G. B.: 3-D numerical modelling of rockfalls in the Lecco urban area (Lombardia Region, Italy), in: Proc. EUROCK 2002, I.S.R.M. International Symposium on Rock Engineering for Mountainous Regions, Madeira, edited by Dinis de Gama, C. and Ribeiro e Sous, L., Sociedade Portuguesa de Geotecnica, 79-86, 2002.

Agliardi, F. and Crosta, G. B.: High resolution three-dimensional numerical modelling of rock falls, Int. J. Rock Mech. Min. Sci., 40/4, 455-471, 2003.

Agliardi, F., Crosta, G. B., Guzzetti, F., and Marian, M.: Methodologies for a physically-based rockfall hazard assessment, Geophysical Research Abstracts, 4, EGS02-A-04594, 2002.

Agliardi, F., Cardinali, M., Crosta, G. B., Guzzetti, F., Detti, R., and Reichenbach, P.: A computer program to evaluate rockfall hazard and risk at the regional scale, Examples from the Lombardy Region, Geophysical Research abstract, 3, 8617, 2001.

Agostoni, S., Laffi, R., Dell'Orsina, F., Pasotti, J., and Sganga, F.: Carta inventario delle frane e dei dissesti della Provincia di Lecco, Regione Lombardia - Provincia di Lecco - Università degli Studi di Milano, GNDCI publication no. 1942, 182 (in Italian), 1999.

Azzoni, A., La Barbera, G., and Zaninetti, A.: Analysis and prediction of rockfalls using a mathematical model, Int. J. Rock Mech. Min. Sci. \& Geomech. Abstr., 32 7, 709-724, 1995.

Bozzolo, D. and Pamini, R.: Simulation of rockfalls down a valley site, Acta Mechanica, 63, 113-130, 1986.

Bozzolo, D., Pamini, R., and Hutter, K.: Rockfall analysis - a mathematical model and its test with field data, Proc. 5th Int. Symposium on Landslides, Lausanne, Switzerland, 1, 555-563, 1988.

Broili, L.: In situ tests for the study of rock fall, Geologia Applicata e Idrogeologia, 8, 1, 105-111 (in Italian), 1973.

Bunce, C. M., Cruden, D. M., and Morgenstern, N. R.: Assessment of the hazard from rockfall on a highway, Can. Geotech. J., 34, 344-356, 1997.

Cancelli, A. and Crosta, G. B.: Hazard and risk assessment in rockfall prone areas, in: Risk Reliability in Ground Engineering, edited by Skipp B.O., Inst. Civ. Eng., Thomas Telford, 177-190, 1993.

Chau, K. T, Wong, R. H. C., and Wu, J. J.: Coefficient of restitution and rotational motions of rockfall impacts, Int. J. Rock Mech. Min. Sci., 39, 69-77, 2002.

Crosta, G. B. and Locatelli, C.: Approccio alla valutazione del rischio da frane per crollo, Proc. Studi geografici e geologici in onore di Severino Belloni, Glauco Brigatti Publisher, Genova, 259-286 (in Italian), 1999.

Crosta, G. B. and Agliardi, F.: Frane di crollo e caduta massi: aspetti geomorfologici, modelli teorici e simulazione numerica, Report EU programme Interreg IIC - Falaises, 119 (in italian), 2000.

Crosta, G. B., Frattini, P., and Sterlacchini, S.: Valutazione e gestione del rischio da frana: principi e metodi, Regione Lombardia Publication, Milano, 169 (in Italian), 2001.

Descouedres, F. and Zimmermann, Th.: Three-dimensional dynamic calculation of rockfalls, Proc. 6th Int. Congress of Rock Mechanics, Montreal, Canada, 337-342, 1987.

Dussauge-Peisser, C., Helmstetter, A., Grasso, J. R., Hantz, D., Desvarreux, P., Jeannin, M., and Giraud, A.: Probabilistic approach to rock fall hazard assessment: potential of historical data analysis, Natural Hazard and Earth System Sciences, 2, 1/2, 1526, 2002.
Einstein, H. H.: Special lecture: Landslide risk assessment procedure, Proc. 5th Int. Symp. on Landslides, Lausanne, 2, 10751090, 1988.

Evans, S. G. and Hungr, O.: The assessment of rockfall hazard at the base of talus slopes, Can. Geotech. J., 30, 620-636, 1993.

Falcetta, J. L.: Un nouveau modle de calcul de trajectoires de blocs rocheux, Revue Francaise de Geotechnique, 30, 11-17 (in French), 1985.

Fell, R.: Landslide risk assessment and acceptable risk, Can. Geotech. J., 31, 2, 261-272, 1994.

Fell, R. and Hartford, D.: Landslide risk management, in: Landslide risk assessment, edited by: Cruden, D., and Fell, R., Balkema, Rotterdam, 51-109, 1997.

Gerber, W.: Direttiva per l'omologazione delle reti paramassi, Ufficio Federale dell'ambiente, delle foreste e del paesaggio (UFAFP), Istituto federale di ricerca WSL, Berna, 39 (in Italian), 2001.

Guzzetti, F.: Landslide fatalities and the evaluation of landslide risk in Italy. Eng. Geol., 58, 89-107, 2000.

Guzzetti, F., Carrara, A., Cardinali, M., and Reichenbach, P.: Landslide hazard evaluation: a review of current techniques and their application in a multi-scale study, Central Italy, Geomorphology, 31, 181-216, 1999.

Guzzetti, F., Crosta, G. B., Detti, R., and Agliardi, F.: STONE: a computer program for the three-dimensional simulatation of rock-falls, Computers and Geosciences, 28, 9, 1081-1095, 2002.

Hungr, O. and Evans, S. G.: Engineering evaluation of fragmental rockfall hazards. Proceedings 5th International Symposium on Landslides, Lausanne, 1, 685-690, 1988.

Hungr, O., Evans, S. G., and Hazzard J.: Magnitude and frequency of rockfalls and rock slides along the main transportation corridors of south-western British Columbia, Can. Geotech. J., 36, 224-238, 1999.

Interreg IIC: Prevenzione dei fenomeni di instabilit delle pareti rocciose. Confronto dei metodi di studio dei crolli nell'arco alpino, Final Report EU Programme Interreg IIC - Falaises, 239 (in French/Italian), 2001

Jones, C. L., Higgins, J. D., and Andrew, R. D: Colorado Rockfall Simulation Program Version 4.0, Colorado Department of Transportation, Colorado Geological Survey, 127, 2000.

Kobayashi, Y., Harp, E. L., and Kagawa, T.: Simulation of rockfalls triggered by earthquakes, Rock Mech. Rock Eng., 23, 1-20, 1990.

Matsuoka, N. and Sakai, H.: Rockfall activity from an alpine cliff during thawing periods, Geomorphology, 28, 309-328, 1999.

Mazzoccola, D. and Sciesa, E.: Implementation and comparison of different methods for rockfall hazard assessment in the Italian Alps, Proc. 8th Int. Symp. On Landslides, Cardiff, Balkema, Rotterdam, 2, 1035-1040, 2000.

Pfeiffer, T. and Bowen, T.: Computer simulation of rockfalls, Bull. Ass. Eng. Geol., 26, 1, 135-146, 1989.

Pierson, L. A., Davis, S. A., and Van Vickle, R.: Rockfall Hazard Rating System Implementation Manual, Federal Highway Administration (FHWA), Report FHWA-OR-EG-90-01, FHWA, U.S. Department of Transportation, 1990.

Ritchie, A. M.: Evaluation of rockfall and its control, Highway Research Board, Highway Res. Rec., 17, 13-28, 1963.

Rochet, L.: Application des modles numériques de propagation a l'étude des éboulements rocheux, Bulletin Liaison Pont Chaussée, 150/151, 84-95 (in French), 1987.

Rouiller, J. D. and Marro, C.: Application de la methodologie Matterock a l'evaluation du danger liè aux falaises, Eclogae Geol. 
Helv., 90, 393-399 (in French), 1997.

Scioldo, G.: Rotomap: analisi statistica del rotolamento dei massi. Guida Informatica Ambientale, Pàtron, Milano, 81-84 (in Italian), 1991.

Spang, R. M.: Protection against rockfall - stepchild in the design of rock slopes, Proc. 6th Int. Congress on Rock Mechanics, Montreal, Canada, 551-557, 1987.

Stevens, W.: RocFall: a tool for probabilistic analysis, design of remedial measures and prediction of rockfalls, M.A.Sc. Thesis, Department of Civil Engineering, University of Toronto, Ontario, Canada, 105, 1998.

Van Dijke, J. J. and Van Westen, C. J.: Rockfall hazard: a geomorphologic application of neighbourhood analysis with Ilwis, ITC Journal, 1990-1, 40-44, 1990.
Varnes, D. J.: Slope movements: types and processes, in: Landslide analysis and control, edited by: Schuster, R. L., and Krizek, R. J., Transportation Research Board, Special Report 176, Washington, DC, 11-33, 1978.

Varnes, D. J. and IAEG Commission on Landslides and other Mass Movements: Landslide hazard zonation: a review of principles and practice, UNESCO Press, Paris, 63, 1984.

Wieczorek, F. G., Morrissey, M. M., Iovine, G., and Godt, J.: Rockfall Potential in the Yosemite Valley, California, U.S. Geological Survey Open-File Report 99-578, 10, 1999.

Wu, S. S.: Rockfall evaluation by computer simulation: Transportation Research Record, Transportation Research Board, Washington, DC, 1031, 1-5, 1985. 